\title{
La noción de "Trans-ibericidade" de Saramago. Una reflexión sobre las relaciones de Portugal y Mexico con España
}

\author{
Graciela ESTRADA VARGAS \\ Universidad Nacional Autónoma de México
}

La noción de Trans-ibericidade que desarrolló Saramago y que ha sido traducida en español como "transiberismo" expresa el deseo de una relación cultural entre la península ibérica y América, África y Asia.

Esta inquietud de Saramago nos permite reflexionar sobre las imágenes que Portugal y México tienen de España, al tiempo que comentamos la "dificultad" del iberismo y nos aproximamos brevemente a la relación entre los países que conforman la península ibérica, y a aquélla entre España y un país americano: México.

Para México, España tuvo el papel de "conquistador", se impuso a los mexicanos. Para Portugal España fue "invasor", ocupó su territorio. No obstante, España tiene afinidades con México y Portugal.

La presente reflexión busca señalar que México y Portugal tienen en común una relación histórica ambigua con España, que sus historias se cruzan y que escritores como Saramago intentaron disminuir los abismos nacidos de las diferencias, para dar lugar al conocimiento mutuo.

Palabras Clave: Saramago, Trans-ibericidade/transiberismo, imagen/imagología, España, Portugal, México.

The idea of Trans-ibericidade developed by Saramago has been translated into Spanish as "transiberismo" and it expresses the desire to establish cultural relations between the Iberian Peninsula and the Americas, Africa and Asia.

The fact that this idea concerned Saramago allows us to reflect on the Portuguese and Mexican images of Spain, while at the same time we mention the difficulties to be overcome in order to achieve an iberismo and we describe briefly the relationship between member countries of the Iberian Peninsula and between Spain and Mexico.

For Mexico, Spain had the role of the "Conqueror" who subjugated the Mexicans. For Portugal, Spain was the "Invader" who occupied their territory. However, Spain has strong affinities with Mexico and Portugal.

This study wants to point outthat Mexico and Portugal have in common an ambiguous historical relationship with Spain, that their histories intersect and that writers like Saramago tried to reduce the abyss of differences to achieve mutual understanding. 
KEY WoRDS: Saramago, Trans/ibericidade, image/imagology, Spain, Portugal, Mexico.

La noción de Trans-ibericidade (Saramago, 1989: 31), que desarrolló Saramago y que ha sido traducida en español como "transiberismo"1 nació de las reflexiones del escritor lusitano sobre la posibilidad de intensificar el conocimiento mutuo entre las nacionalidades que habitan la península ${ }^{2}$ ibérica. Tras prever que dicha posibilidad se vería confrontada a la indignación patriótica de los nacionalismos, en especial del lado español, que no desearían formar parte de un "caldo ibérico", Saramago desplazó su interés hacia América Latina:

[... ] por efeito reflexo da decepção sofrida ao querer chegar a um entendimento [... ] do [... ] universo ibérico, viraram-se-me os melancólicos olhos para a América Latina (Saramago, 1989: 31).

Como efecto reflejo de la decepción sufrida al querer llegar a un entendimiento [... ] del universo ibérico, mis ojos melancólicos voltearon hacia América Latina. ${ }^{3}$

Del continente americano el autor afirmó conocer novelistas y poetas, así como la historia y geografía. La noción de trans-ibericidade expresa el deseo de una relación cultural, aunque no solamente cultural, entre la península ibérica y América, África y Asia (Urrutia, 2001: 26):

[... ] a própria Península Ibérica não poderá ser hoje plenamente entendida fora da sua relação histórica e cultural com os povos de além (Saramago, 1989: 31).

Hoy la propia península ibérica no podría ser entendida plenamente fuera de su relación histórica y cultural con los pueblos extranjeros.

La aventura de la novela A Jangada de Pedra (1986), publicada en español como La balsa de piedra, narra la separación de la península ibérica del continente y su desplazamiento hacia el sur a través del Atlántico. Esta obra puede ser vista como la alegoría de la ideología de Saramago, que parece haber encontrado su inspiración en la imagen de Eugenio d'Ors que describe a Portugal como un "balcón abierto al infinito" (Pageaux, 1998: 163). Cabe mencionar que los personajes de A Jangada de Pedra, portugueses y españoles, sobreviven gracias a su unión y solidaridad.

La imagen de un puente que uniría la península ibérica y América Latina es también retomada por un autor mexicano, Carlos Fuentes, en el texto "Iberoamérica", incluido

\footnotetext{
${ }^{1}$ Como en Jorge Urrutia (2001: 26), o bien como “trans-iberismo" en César Antonio Molina (1990: 7).

2 Escribo "península ibérica" con minúscula, como lo hace María Moliner en su Diccionario de uso del español.

${ }^{3}$ Las traducciones propuestas son aproximativas.
} 
en En esto creo: “Creo en Iberoamérica. El Atlántico no es para mí abismo, sino puente. Las aguas del Mediterráneo fluyen del Bosforo y Andalucía a las Antillas y el Golfo de México" (Fuentes, 2002: 118).

No obstante, la trans-ibericidade saramaguiana está ligada a la imposibilidad de un "iberismo", 4 esto es, de un espacio ibérico en el que la relación entre la nación lusitana y el resto de nacionalidades peninsulares sería multilateral y daría lugar a la intensificación de un conocimiento mutuo (Urrutia, 2001: 26; Saramago, 1990: 7):

[... ] finalmente: $\mathrm{O}$ iberismo está morto? Sim.

Poderemos viver sem um iberismo? Não o creio

(Saramago, 1989: 31).

Finalmente, ¿el iberismo está muerto? Sí.

¿Podremos vivir sin un iberismo? No lo creo.

Constatar esto, que fuera además uno de los argumentos que nutrió el escepticismo de Saramago respecto a la Comunidad Europea (Saramago, 1998 [1993, 22 de junio]: 88) permite abrir un paréntesis a fin de hablar de la relación entre España y los mundos portugués y latinoamericano, específicamente el mundo mexicano. Este tema, en el que no pretendemos profundizar ahora, debe ser mencionado, lo mismo que ciertas nociones y definiciones con las que se relaciona.

Entendemos por imagen comparatista "la expresión, sea o no literaria, de un diferencia significativa entre dos órdenes de la realidad cultural" (Pageaux, 1994: 60). Es el resultado de la toma de conciencia de la diferencia de un Yo en relación con un Otro. Su espacio y tiempo son heterogéneos (Pageaux, 1971: 16).

La imagen que un pueblo se forma de una nación extranjera está ligada a sentimientos e ideas extremadamente profundas o vividas. Esta imagen es una lectura ${ }^{5}$ de ese país. No obstante, hay que subrayar que no existe una sola sino varias lecturas posibles y simultáneas, ellas son tan diversas como las actitudes mentales, ios niveles culturales, los grupos sociales o los intereses de clase.

Con base en la cita siguiente, podemos decir que en la imagen de los hispanos en Portugal hay una distorsión resultado de un sentimiento de enemistad:

Como qualquer outro português antigo e moderno, fui instruido na convicção firme de que o meu inimigo natural era, e sempre haveria de ser, Espanha (Saramago, 1989: 29).

4 El iberismo fue un tema de interés durante los siglos XIX y XX en España y Portugal. Del lado español escritores como Clarín, Valera, Ganivet, Emilia Pardo Bazán, Eugenio D’Ors y Gómez de la Sema hablaron de un iberismo cultural, y Valle-Inclán trató del mismo a nivel del Estado. Del lado portugués, Oliveira Martins, Antonio Sardinha y Almada Negreiros mostraron su interés al respecto (Molina, 1990: 267).

$5 \quad$ El país emisor de la imagen también puede ser nombrado pueblo o grupo observador ("groupe regardant"), y el país objeto será el "país observado" (“pays regardé”) o "país leído" ("pays lu”) (Pageaux, 1971: 15-16). 
Como cualquier otro portugués antiguo y moderno, fui instruido en la convicción firme de que mi enemigo natural era, y siempre tendría que ser, España.

El estudio de una imagen permite conocer el país emisor de ésta. En este caso, la imagen que Portugal tiene de España abre una puerta para acceder a la ideología portuguesa.

Saramago habló de su novela A Jangada de Pedra como el "fruto inmediato del resentimiento portugués por el histórico desdén de Europa" (Saramago, 1999: 15). Tras un breve examen del léxico de la cita precedente, llaman la atención las palabras "enemigo" y "natural". ${ }^{6}$ El Nobel portugués veía, no sin ironía, que quizá el rencor hacia el país vecino ha ayudado a formar la identidad portuguesa (Saramago, 1989: 29). El autor sabía que esta hipótesis, justificada desde cierto punto de vista por las invasiones españolas, ${ }^{7}$ era relativa pues Portugal vivió también invasiones inglesas y francesas.

Por su parte, Fuentes ve un tipo de peligro en el rencor y el aislamiento de América Latina con respecto a España, pero también en la relación que España sostiene con América Latina. La asimilación de las tradiciones indo afro ibéricas ${ }^{8}$ por los países latinoamericanos permitiría "llenar el abismo de rencores" y "reconocerse en nuestra otra mitad que es España" (Fuentes, 2002: 121-122).

Octavio Paz hablaba en El laberinto de la soledad de la relación histórica ambigua entre México y España; constataba igualmente las diferencias. 9 Fuentes reflexiona también sobre el tema al inicio de su ensayo Cervantes o la crítica de la lectura (1976), en su novela Terra nostra (1975) y en el ensayo El espejo enterrado (1992).

Para el estudioso comparatista D. H. Pageaux (Pageaux, 1994: 19) existen dos tipos de relaciones posibles entre las naciones: por una parte las relaciones unilaterales que comprenden la "manía" (cuando el país leido es admirado) y la "fobia" (cuando el país leído es visto como inferior), y por otra parte las relaciones bilaterales, como la "filia" (cuando hay estima mutua) y el "intercambio" (cuando hay una circulación de influencias positivas y negativas).

Las filias y fobias de las excolonias como México con relación a España no pueden ser el resultado de la indiferencia. El hecho de que el monarca actual Juan Carlos I haya sido el primer rey español en visitar América (Fuentes, 2002: 119) es con certeza la

\footnotetext{
6 Nociones similares son "enemigo hereditario" ("ennemi héréditaire"), "enemigo ocasional" ("ennemi occasionnel"), "amigo incondicional" ("ami inconditionnel") y "amigo temporal" ("ami temporaire"), nociones de las que el comparatista debe desconfiar en un estudio de imagología, para no caer en una explicación maniquea (Pageaux, 1971: 18-19). Es aconsejable el estudio de relaciones unilaterales (manía et fobia) (manie et phobie) y bilaterales (filia e intercambio) (philie et échange), como lo haremos más adelante.

${ }^{7}$ En la época de Dom Alfonso Henriques o Alfonso I de Portugal que luchó contra las pretensiones del español Alfonso VII de León y Castilla que buscaba la hegemonía peninsular en el siglo XII.

8 Terra nostra (1975) y Cervantes o la crítica de la lectura muestran el interés de Fuentes por la historia y la identidad indo afroiberoamericana.

9 "Proyecto y utopía son inseparables del pensamiento hispanoamericano [...] elegía y crítica son inseparables del pensamiento peninsular" (Paz, 1993).
} 
prueba de indiferencia, pero también marca el interés dado a los países latinoamericanos que se manifiesta igualmente en las actividades organizadas por los centros culturales, como el Instituto Cervantes o los premios otorgados a artistas.

En cuanto a Portugal, fue ignorado ${ }^{10}$ por otros países a lo largo de su historia, pero él igualmente los ignoró. Su relación con Francia en el siglo XVIII proporciona un ejemplo:

[... ] des relations franco-portugaises: rarement celles-ci descendent le fleuve Inclination; on les voit plus volontiers s'échouer, pendant le XVIIInème siècle, dans la mer d'inimitié ou dans le lac d'indifférence (Pageaux, 1971: 27).

[... ] las relaciones franco portuguesas: rara vez descienden el río Inclinación; durante el siglo XVIII, las vemos con más tendencia a fracasar en el mar de la Enemistad o en el lago de la Indiferencia.

Además, esta relación pobre o débil con Francia se explica por la que esta última mantenía con el "enemigo secular" portugués: España, considerada como la "amiga de Francia”. Traducida en términos comparatistas, la imagen que Portugal tenía de Francia y viceversa estaba deformada por la relación de esta última con España.

Las razones o motivaciones de esos periodos de hispanofobia e hispanofilia que conocieron Portugal y México no son las mismas, pero están presentes hoy en día: ${ }^{11}$ para prueba un proverbio portugués todavía en uso: "De Espanha nem bom vento, nem bom casamento", "De España ni buen viento ni buen casamiento".

Para México, España tuvo el papel de "conquistador", ${ }^{12}$ se impuso a los mexicanos. ${ }^{13}$ Para Portugal, España fue "invasor", ocupó su territorio y desconoció su autonomía. No obstante, España comparte con México un cierto número de puntos como el predominio de la religión católica, una historia política marcada por la dictadura, la lengua o incluso los hábitos culinarios, y con Portugal, la religión y una distancia con respecto a Europa.

Un texto del escritor español Antonio Gala, dirigido al expresidente portugués Jorge Sampaio, ${ }^{14}$ habla de esa relación paradoxal entre el país en el que nació Saramago y el país en el que residió. El texto propone una filia entre los pueblos de la península ibérica:

${ }^{10}$ Como ejemplo, existían en el siglo XVIII un eje económico París-Madrid-Cádiz que ignoraba a Portugal (Pageaux, 1971: 27).

11 En la actualidad marcada por los movimientos migratorios, el sobrenombre peyorativo de "sudacas" es aplicado en España a los inmigrantes de origen latinoamericano. En cuanto a los españoles instalados en los países hispanoamericanos, son llamados "gachupín” o "cachupín” (Moliner: 1360).

12 "Vue du côté du Nouveau Monde, la Découverte est une Conquête, c'est-à-dire un acte de violence

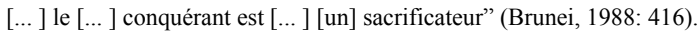

13 Kundera escribe que Occidente domino a América Latina mediante la Conquista y por ello su legitimidad ahí será siempre cuestionada (Kundera, 2006: 20).

${ }^{14}$ El doctor Jorge Sampaio fue presidente de 1996-2006. 
Portugal y España, en su historia, no dejaron nunca de abrazarse. Ningún país se encuentra más cerca y, al mismo tiempo, pocos están tan distantes. Con ríos comunes y desdenes europeos comunes. Con geografías semejantes y desarrollos muy parecidos; siendo España el primer invasor en Portugal [... ] significando en la cultura de Europa un ideal idéntico, no cabe en cabeza humana [... ] que tantas apariencias nos dividan (Saramago, 1998 [1993]: $31^{15}$ ).

Esta reflexión permite ver que México y Portugal tienen en común una relación histórica ambigua con España, que sus historias se cruzan con aquélla del país de Cortés y de Cervantes y que escritores como Fuentes y Saramago intentan disminuir, borrar los abismos nacidos de las diferencias, para dar lugar al diálogo y al conocimiento mutuo.

\section{Obras citadas}

AlfaDA, Javier. 1993. "O compromisso moral e político na obra de José Saramago ou um lector espanhol perante Saramago". Vértice, núm. 52, 2a. serie, enero-febrero. Pp. 23-27.

BRUNEL, Pierre. 1988. Dictionnaire des mythes littéraires. Lonrai: Ediciones du Rocher.

FuENTES, Carlos. 2002. En esto creo. México: Seix Barral. (Col. Biblioteca Breve) . 1992. El espejo enterrado. México: FCE. (Col. Tierra firme)

. 1976. Cervantes o la crítica de la lectura. México: Joaquín Mortiz.

1975. Terra nostra. Madrid: Planeta de Angostini.

KunderA, Milan. 2006. "Esch est Luther". Claude Fell, comp., Fuentes. París: L'Herne.

Molina, César Antonio. 1990. Sobre el iberismo y otros escritos de literatura portuguesa. Madrid: Akal.

Moliner, María. Diccionario del uso del español. Madrid: Gredos. 2 vols.

PageauX, Daniel-Henri. 1998. “La péninsule Ibérique et l'Europe”. Dir. Béatrice

DIDIER, Précis de Littérature européenne. Paris: PUF. Pp. 161-166. . 1994. La littérature générale et comparée. Paris: Armand Colin. (Col. Cursus) . 1971. "Images du Portugal dans les lettres françaises (1700-1755)". Memorias

e Documentos para a Historia Luso-francesa-VII. Paris / Coimbra: Fundação Calouste Gulbenkian. Pp. 13-45.

PAZ, Octavio. 1993. El laberinto de la soledad, Posdata. Vuelta al laberinto de la soledad. México: FCE.

SARAMAGO, José. 1999. "De como los personajes se convirtieron en maestros y el autor en aprendiz”. Letra internacional, núm. 60. Madrid, enero-febrero.

15 Publicado originalmente en El Mundo el 23 enero 1993, transcrito y citado por Saramago en Cuadernos de 1993. 
. 1998. Cuadernos de Lanzarote /. 1993-1995. Madrid / México: Alfaguara. . 1990. "Prólogo". César Antonio Molina, Sobre el iberismo y otros escritos de literatura portuguesa. Madrid: Akal. Pp. 4-9, y entrevista pp. 247-275. . 1989. “Acerca do (meu) Iberismo". Encontros: Revista Hispano Portuguesa de Investigadores en Ciencias Humanas y Sociales, núm 1. Olivenza / Badajoz. Pp. 29-31. . 1986. A Jangada de Pedra. Lisboa: Caminho.

URRUTIA, Jorge. 2001. "José Saramago. Notoriedad del iberismo España descubre Portugal”. Leer, núm. 125, verano, año XVII. Madrid, septiembre. Pp. 26-30. 